\title{
Pregnancy related back pain, is it related to aerobic fitness? A longitudinal cohort study
}

Eva Thorell ${ }^{1,2+}$ and Per Kristiansson ${ }^{1 *+}$

\begin{abstract}
Background: Low back pain with onset during pregnancy is common and approximately one out of three women have disabling pain. The pathogenesis of the pain condition is uncertain and there is no information on the role of physical fitness. Whether poorer physical conditioning is a cause or effect of back pain is also disputed and information from prospective studies needed.
\end{abstract}

Methods: A cohort of pregnant women, recruited from maternal health care centers in central Sweden, were examined regarding estimated peak oxygen uptake by cycle ergometer test in early pregnancy, reported physical activity prior to pregnancy, basic characteristics, back pain during pregnancy and back pain postpartum.

Results: Back pain during the current pregnancy was reported by nearly $80 \%$ of the women. At the postpartum appointment this prevalence was $40 \%$. No association was displayed between estimated peak oxygen uptake and incidence of back pain during and after pregnancy, adjusted for physical activity, back pain before present pregnancy, previous deliveries, age and weight. A significant inverse association was found between estimated peak oxygen uptake and back pain intensity during pregnancy and a direct association post partum, in a fully adjusted multiple linear regression analysis.

Conclusions: Estimated peak oxygen uptake and reported physical activity in early pregnancy displayed no influence on the onset of subsequent back pain during or after pregnancy, where the time sequence support the hypothesis that poorer physical deconditioning is not a cause but a consequence of the back pain condition. The mechanism for the attenuating effect of increased oxygen uptake on back pain intensity is uncertain.

\section{Background}

Chronic medical conditions are in focus for the development of strategies aimed at improving population health worldwide. This is also true for chronic pain conditions leading to impaired or non-existent ability to exercise, as physical inactivity is associated with development of chronic diseases. Musculoskeletal disorders constitute an estimated $90 \%$ of all chronic pain, of which back pain contributes to a high extent.

During pregnancy there is a remarkably increased prevalence of low back pain, as compared with the nonpregnant state. Prevalence rates between $61 \%$ and $88 \%$ of back pain with onset during current pregnancy are

\footnotetext{
* Correspondence: per.kristiansson@pubcare.uu.se

+ Contributed equally

'Department of Public Health and Caring Sciences, Family Medicine and Preventive Medicine unit, Uppsala University, Box 564, SE-751 22 Uppsala, Sweden

Full list of author information is available at the end of the article
}

reported, as compared with one-year prevalence of back pain, irrespective of onset, among women of the same age of $40 \%$ in the general population. This means that a high proportion of women with previously healthy backs experience onset of back pain in pregnancy. The pregnancy related back pain varies from mild discomfort to severely debilitating pain of several months' duration [1-3]. In most women, pregnancy-related back pain disappears during the first six months after delivery. However, a fairly high proportion still experience low back pain that seriously interferes with daily activities two years after childbirth [4-7].

The cause and pathogenesis of the development and course of pregnancy related low back pain remain uncertain. Known determinants of pregnancy related low back pain are previous pregnancies and deliveries, hormonal contraceptive use before first pregnancy, physically demanding work and emotional distress [8-10]. 
However, the fraction of explained variance of these factors is small.

Whether physical inactivity causes low back pain or whether low back pain causes patients to decrease their physical activity and become physically weaker is disputed [11]. Smeets et al. [12] reported that patients with moderately to severely disabling low back pain had lower aerobic fitness levels than healthy subjects matched for age, sex and physical activity. As in other studies, a cross-sectional design was used, which means that the timing of the onset of poorer physical condition was unclear. Prospective research on healthy subjects has not identified low activity or fitness levels as significant risk factors for developing chronic low back pain [12]. Physical fitness levels can be assessed by submaximal incremental exercise methods, such as cycle ergometer test, which have shown good agreement with oxygen uptake measured with gas analyses as gold standard [13-15].

Thus a cohort study of women followed from early pregnancy to postpartum was identified in order to study the cause and effect mechanism of physical fitness and development of pregnancy related low back pain. The purpose of the present study was to evaluate the effects of physical fitness in early pregnancy, measured as estimated peak oxygen uptake by cycle ergometer test and reported physical activity prior to pregnancy, on the development and course of back pain during pregnancy and after delivery.

\section{Methods \\ Setting}

Female residents of Sweden have the right to attend a maternal health center during pregnancy free of charge. The centers are operated by the county councils, or are subcontracted to the councils. Some of the centers are located at hospitals, others in the community. They are staffed by general practitioners, midwives and administrative staff. They all follow the same general procedure with repeated appointments during pregnancy, and one postpartum.

\section{Study population}

Between March 27, 2001 and June 5, 2003, all women in early pregnancy who attended eight maternal health centers in the city of Örebro (population 128,000), and two each in the municipalities Kumla and Hallsberg (populations 20,000 and 15,000) close to Örebro, were identified, a total of 2,085 women. As shown in Figure $1,1,350$ women declined participation in the study or were excluded for various reasons, leaving 735 women who agreed to participate. Of these, 215 did not take the cycle ergometer test, leaving a final study population of 520 women.
Participation rates across the centers ranged from 40\% to $70 \%$. Information on non-participating women was retrieved from the medical records of the maternal health centers. None of the main variables used in the study showed any statistically significant association with participation rate.

\section{Data collection}

Data were collected at four appointments, on average at 10.9 (range 5-21), 24.0 (range 18-26), 29.7 (range 27-34), 36.5 (range 35-40) completed gestational weeks, and 21.2 (range 12-54) weeks postpartum. Information was sought about basic physical characteristics, physical activity and oxygen uptake during and after pregnancy.

At the first appointment height was measured without shoes with a wall-mounted tape measure to the nearest centimeter. Weight was measured at all appointments with indoor clothing without shoes on a lever balance, as kilograms to one decimal. The women completed a questionnaire on leisure time physical activity undertaken to maintain or improve fitness or health during the past four weeks at the first and last appointments. The frequency of physical activity was classified as never (= $1)$, now and then $(=2)$, once or twice a week $(=3)$, three to five times a week $(=4)$, or more than five times a week $(=5)$. Previous back pain which led to consultation of a physician, physiotherapist, or chiropractor was recorded.

From the second appointment onwards, the location of pain was indicated by the women on a pain sketch. More than one location could be indicated. The back locations were coded as cervical spine, thoracic spine, lumbar spine, lumbosacral spine and sacral spine. In addition, the current back pain intensity was measured on a visual analogue scale (VAS) $100 \mathrm{~mm}$ long; $0 \mathrm{~mm}$ indicating no pain and $100 \mathrm{~mm}$ indicating intolerable pain. Reported pain intensities were attributed to the respectively reported pain locations.

Aerobic capacity was estimated with the submaximal cycle ergometer heart rate method (Monark Exercise Ergometer $828 \mathrm{E}$ bicycle, adjustable to individual height), at the first and last appointment, held some time between 8 a.m. and 4.30 p.m., under supervision of the same experienced test administrator (KA). During the test, the women wore light clothing and sport shoes. Room temperature was $18-20^{\circ} \mathrm{C}$. The women were instructed not to eat a light meal one hour before or a heavy meal 2-3 h before test, and to avoid strenuous physical activity for one day before test. Nicotine use was not allowed for one hour prior to the test. In case of an on-going infectious disease the test was postponed for two weeks. Heart rate was determined every minute using a wireless chest pulse belt. A pedaling rate of 50 revolutions per minute was kept constant by use of a 


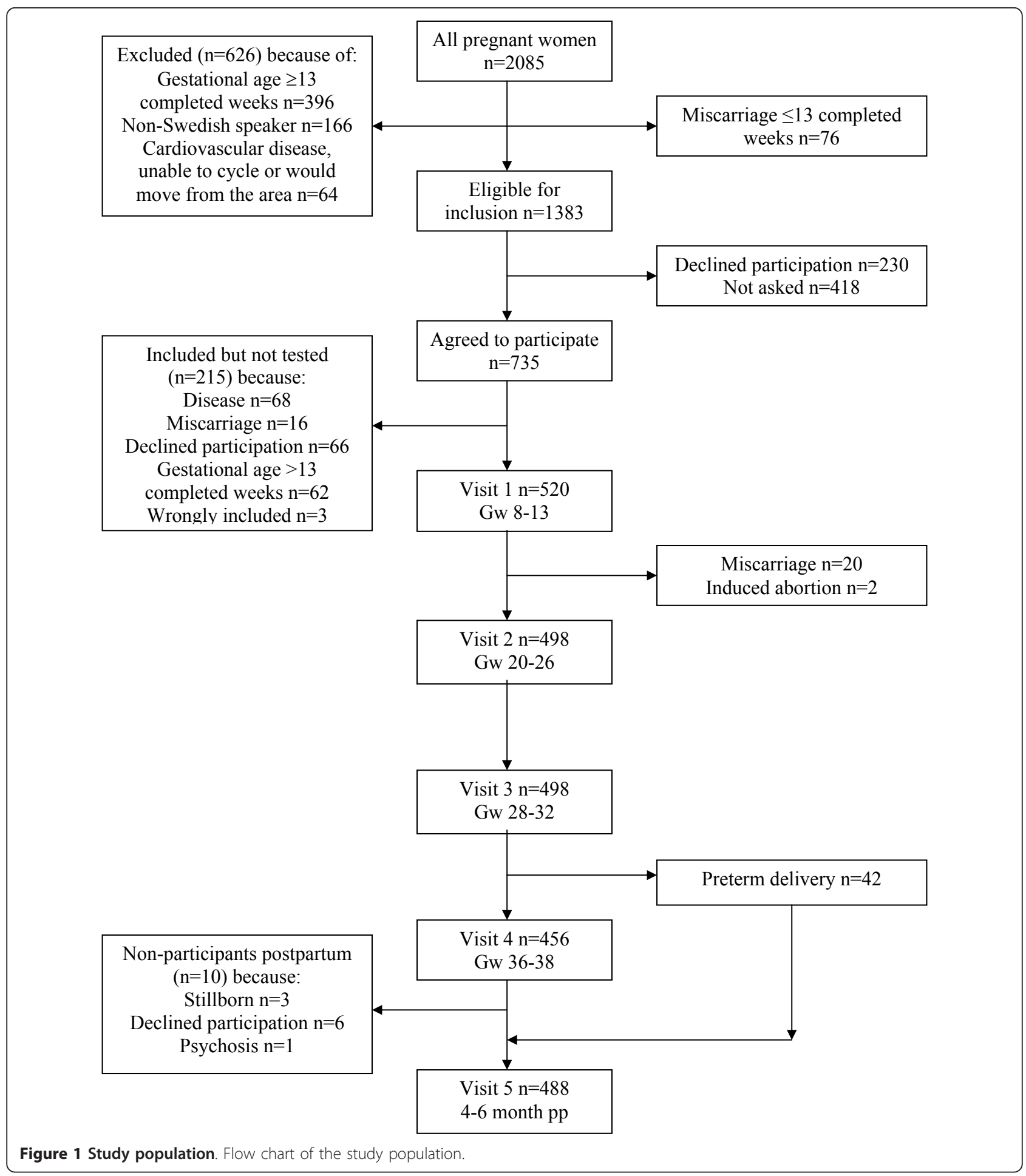

metronome. Initial workload, $50 \mathrm{~W}$ or $75 \mathrm{~W}$, was based on the women's reported physical activity levels, and increased by $25 \mathrm{~W}$ per minute until a steady state heart rate of 125 .beats or more-per minute was reached, after which the women cycled for at least 6 min until two consecutive heart rates, one minute apart, differed by 3 or fewer beats.per minute. The heart rate values obtained were used to estimate absolute peak oxygen

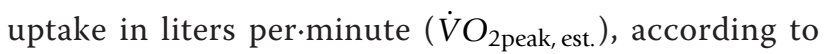
the Åstrand and Ryhming nomogram [16].

The Research Ethics Committee of Örebro University, Sweden, approved the study. 


\section{Statistical analysis}

Statistical analyses were performed using the SAS software, version 9.2 (SAS Institute Inc., Cary, NC, USA). Means and proportions were calculated using standard techniques. For the regression analyses data on reported back pain or no back pain from each visit and women's estimates of pain intensity were concatenated to create a data set consisting of pain reports and the corresponding pain intensity estimates throughout pregnancy. Cox regression and General Linear Model were used for regression analysis, and the latter also to produce a model and figure of adjusted back pain intensity by absolute $V \mathrm{O}_{2 \text { peak, est. }}$ No multicollinearity problem was found. Only two-tailed tests were used. Statistical tests were considered significant if $\mathrm{p}<0.05$.

\section{Results}

Characteristics of the study population are shown in Table 1. Almost half the women reported physical activity at least once a week and the mean absolute

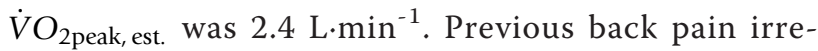
spective of pregnancy was reported by nearly half of the women and $8 \%$ reported sickness absence because of back pain before the present pregnancy. Back pain of any location at any point during present pregnancy was reported by almost 8 out of 10 women, with lumbosacral and sacral pain as the most commonly reported locations. At the postpartum visit the prevalence of any reported back pain was half or that reported during pregnancy. The mean intensity of back pain increased successively by gestational age to maximum $39 \mathrm{~mm}$ on the VAS in late pregnancy, and subsequently declined to $18 \mathrm{~mm}$ at 22 weeks postpartum.

The number and proportion of women reporting back pain at each appointment during and after pregnancy are shown in Table 2. During pregnancy the prevalence rates of cervico-thoracic and lumbar pain locations were $<10 \%$, without significant changes postpartum. The corresponding prevalence rates of lumbosacral and sacral pain were stable at about $30-37 \%$ during pregnancy and displayed a significant decrease $(\mathrm{p}<0.0001)$ at the postpartum appointment to $24 \%$ and $11 \%$, respectively. The proportion of women with more than one back pain location were at the pregnancy visits between $14 \%$ and $17 \%$ and at the postpartum visit $11 \%$.

\section{Association between back pain and possible determinants in early pregnancy}

Cox regression analysis showed no association between the hazard (incidence) of back pain in any back pain location during pregnancy or back pain location at the postpartum visit on the one hand and absolute $\dot{V} O_{2 \text { peak, est. }}$ measured in early pregnancy on the other.
Table 1 Characteristics of all 520 women included in the study

\begin{tabular}{lll}
\hline Characteristic & $\mathbf{n}$ & $\begin{array}{l}\text { Mean or } \\
\text { proportion }\end{array}$ \\
\hline $\begin{array}{l}\text { Absolute } \dot{V} \mathrm{O}_{2 \text { peak, est. }} \text { early pregnancy } \\
(\mathrm{L} / \mathrm{min})\end{array}$ & 520 & $2.4(0.5)$ \\
\hline Physical activity $\geq$ once a week (\%) & $\begin{array}{l}259 / \\
520\end{array}$ & 49.8 \\
\hline Previous back pain, irrespective of & $238 /$ & 45.8 \\
pregnancy (\%) & 520 & \\
\hline Sick-leave due to back pain before & $43 / 520$ & 8.3 \\
pregnancy (\%) & & \\
\hline No previous pregnancy (\%) & $218 /$ & 41.9 \\
& 520 & \\
\hline No previous delivery (\%) & $258 /$ & 49.6 \\
& 520 & \\
\hline Age (yr) & 520 & $29.0(4.4)$ \\
\hline Weight, gestational week 12 (kg) & 520 & $68.1(12.6)$ \\
\hline Height (m) & 520 & $1.67(0.06)$ \\
\hline University education (\%) & 520 & 43.9 \\
\hline Current smoker (\%) & 520 & 18.5 \\
\hline Back pain location throughout resent & & \\
\hline
\end{tabular}

Back pain location throughout present pregnancy:

\begin{tabular}{lll}
\hline Cervico-thoracic (\%) & $69 / 459$ & 15.0 \\
\hline Lumbar (\%) & $67 / 459$ & 14.6 \\
\hline Lumbosacral (\%) & $274 /$ & 58.2 \\
& 471 & \\
\hline Sacral (\%) & $253 /$ & 53.9 \\
& 469 & \\
\hline Any back pain location (\%) & $373 /$ & 77.9 \\
& 479 & \\
\hline Back pain of any location postpartum (\%) & $179 /$ & 36.7 \\
& 488 &
\end{tabular}

\begin{tabular}{ccc}
\hline Back pain intensity $(\mathrm{mm})$ & & \\
\hline Gestational week 24 & 498 & $33.7(31.5)$ \\
\hline Gestational week 30 & 497 & $38.0(31.3)$ \\
\hline Gestational week 36 & 455 & $39.2(32.0)$ \\
\hline Post partum week 22 & 488 & $18.3(26.8)$ \\
\hline
\end{tabular}

Back pain = cervico-thoracic, lumbar, lumbosacral or sacral pain location. $\dot{V} \mathrm{O}_{2 \text { peak, est. }}=$ estimated peak oxygen uptake.

However, an inverse significant association was displayed with age and back pain during pregnancy (HR $0.96, \mathrm{p}=0.0005)$ and back pain during pregnancy and postpartum (HR 0.96, $\mathrm{p}=0.0007$ ). Analyses including possible confounding factors did not change these findings.

Possible determinants in early pregnancy of intensity of back pain during pregnancy are shown in Table 3. In the univariate regression analyses absolute $\dot{V} O_{2 \text { peak, est. }}$, physical activity, age and university education were significantly inversely associated and previous back pain, previous deliveries, weight and current smoking was significantly positively associated with back pain intensity. 
Table 2 Prevalence of back pain during and after pregnancy by back pain location

\begin{tabular}{|c|c|c|c|c|c|c|c|c|c|c|c|c|c|}
\hline \multirow[b]{3}{*}{ Time } & \multirow[b]{3}{*}{$\mathbf{N}$} & \multicolumn{12}{|c|}{ Back pain location } \\
\hline & & \multicolumn{2}{|c|}{$\begin{array}{l}\text { Cervico- } \\
\text { thoracic }\end{array}$} & \multicolumn{2}{|c|}{ Lumbar } & \multicolumn{2}{|c|}{$\begin{array}{l}\text { Lumbo- } \\
\text { sacral }\end{array}$} & \multicolumn{2}{|c|}{ Sacral } & \multicolumn{2}{|c|}{$\begin{array}{l}\text { More than } \\
\text { one location }\end{array}$} & \multicolumn{2}{|c|}{$\begin{array}{c}\text { Any } \\
\text { location }\end{array}$} \\
\hline & & $\mathrm{n}$ & $\%$ & $n$ & $\%$ & $\mathrm{n}$ & $\%$ & $\mathrm{n}$ & $\%$ & $\mathrm{n}$ & $\%$ & $\mathrm{n}$ & $\%$ \\
\hline Gw 24 & 498 & 30 & 6 & 28 & 6 & 157 & 32 & 152 & 30 & 69 & 14 & 278 & 56 \\
\hline Gw 30 & 497 & 40 & 8 & 33 & 7 & 185 & 37 & 157 & 32 & 86 & 17 & 306 & 62 \\
\hline Gw 36 & 455 & 39 & 8 & 26 & 6 & 161 & 35 & 142 & 31 & 78 & 17 & 263 & 58 \\
\hline $22 \mathrm{wpp}$ & 488 & 52 & 11 & 36 & 7 & 120 & 24 & 53 & 11 & 53 & 11 & 179 & 37 \\
\hline
\end{tabular}

Number and proportion of women reporting back pain during and after pregnancy by back pain location. Gw gestational week. $N$ total number of women, $n$ number of women with the actual back pain location.

In a multiple linear regression analysis all factors remained significant except university education and current smoking. The $\mathrm{R}^{2}$ of the full model was 0.12 . A multiple linear regression analysis was similarly performed to find determinants for pain intensity at the postpartum appointment: back pain before pregnancy was significantly and positively associated with pain intensity but neither of the other factors (data not shown). The $\mathrm{R}^{2}$ of that model was 0.07 .

\section{Association between back pain intensity and oxygen uptake}

To illustrate the effect of absolute $\dot{V} O_{2 p e a k, \text { est. on }}$ reported back pain intensity, during and after pregnancy, the women were grouped by absolute $\dot{V} O_{2 \text { peak, est. into }}$ tertials as, 1.3 to $2.1,2.2$ to 2.6 and 2.7 to $4.4 \mathrm{~L} / \mathrm{min}$. The pain intensity scores during pregnancy (adjusted by the independently significant determinants reported physical activity, previous back pain, previous delivery,

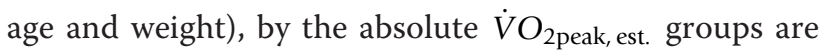
presented in Figure 2. From the group with the lowest

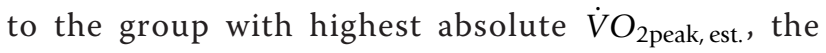
mean back pain intensity scores decreased in a doseresponse manner, from $40 \mathrm{~mm}$ to $32 \mathrm{~mm}$ with significant differences between the group with the lowest

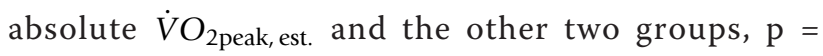
0.0003 and $\mathrm{p}=0.004$, respectively. After delivery the

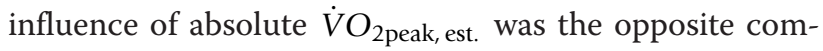
pared with during pregnancy, but no significant difference was shown.

\section{Discussion}

In this prospective cohort study, oxygen uptake and physical activity in early pregnancy displayed no influence on the onset of back pain during or after pregnancy, while among women reporting pregnancy related back pain physical fitness attenuated the intensity of pregnancy related back pain throughout the pregnancy but not after delivery. This speaks for the hypothesis that poorer physical condition in combination with back pain is not a cause but a consequence of the pain condition.

The strengths of the present study were the prospective approach, use of validated methods and the number of participants who performed the cycle ergometer test. One limitation of the study was the number of non-participants. However, there was no difference in the main variables between participants and non-participants. Hence, it would probably be possible to extrapolate the results of the present study to healthy pregnant women in general. The lack of more precise information on the

Table 3 Effects on back pain intensity of factors in early pregnancy in linear regression analyses

\begin{tabular}{lllll}
\hline & Crude & & Adjusted & p \\
\hline Covariates & Estimate & Estimate & 0.0019 \\
\hline Absolute $\dot{V} O_{\text {2peak, est. }}(\mathrm{L} / \mathrm{min})$ & -6.0 & 0.0003 & -5.2 & $<0.0001$ \\
\hline Physical activity & -4.8 & $<0.0001$ & -3.3 & $<0.0001$ \\
\hline Previous back pain & 13.3 & $<0.0001$ & 12.6 & 0.0006 \\
\hline Previous delivery & 4.5 & $<0.0001$ & 4.1 & $<0.0001$ \\
\hline Age (yr) & -0.9 & $<0.0001$ & -1.3 & $<0.0001$ \\
\hline Weight (kg) & 0.4 & $<0.0001$ & 0.3 & 0.35 \\
\hline University education & -3.1 & $<0.0001$ & -0.6 & 0.66 \\
\hline Current smoking & 3.4 & 0.019 & -0.6 & \\
\hline
\end{tabular}

$\dot{\mathrm{VO}} \mathrm{2peak}_{\text {, est. }}=$ estimated peak oxygen uptake. 


\section{Mean back pain intensity scores by groups of oxygen uptake}

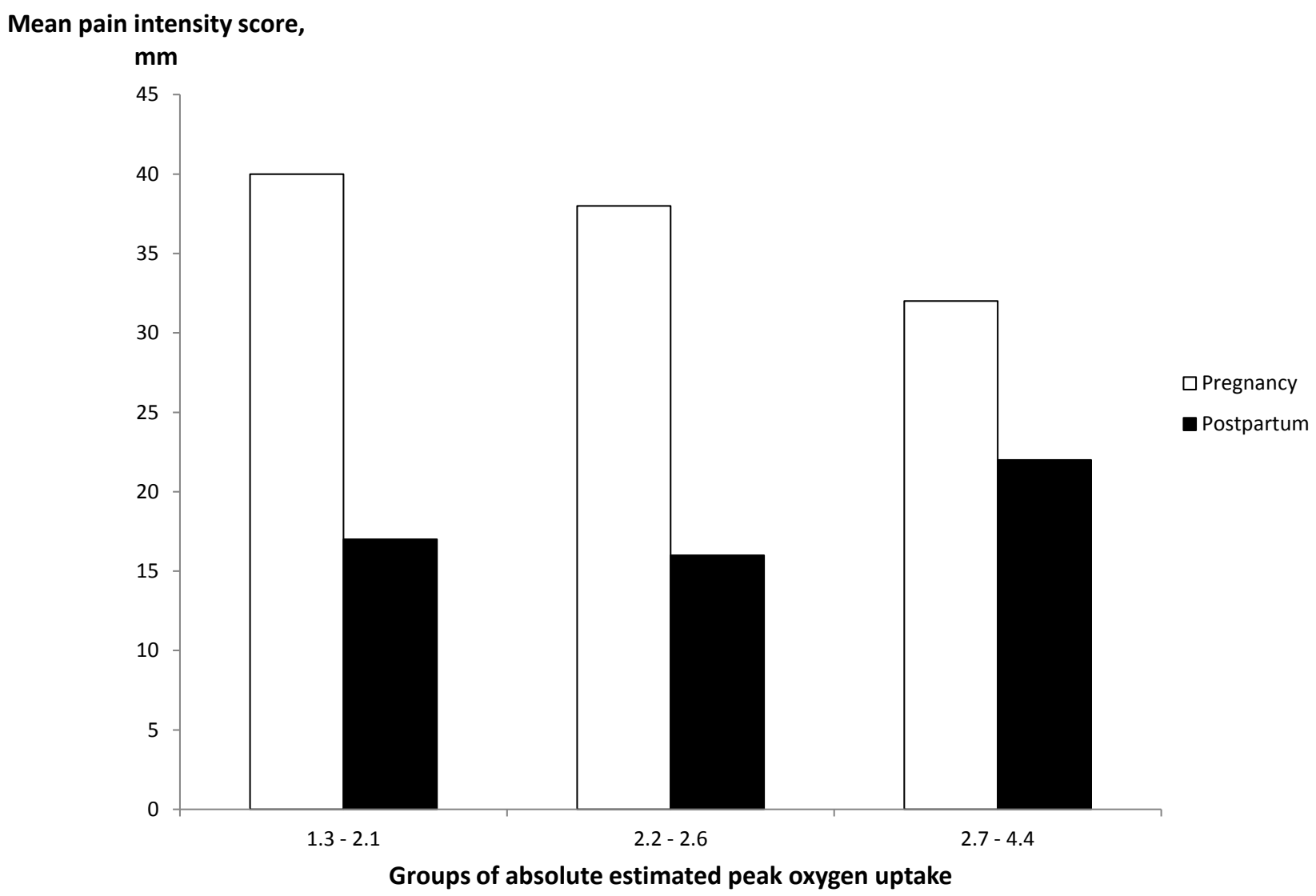

Figure 2 Outcome measure. Mean of back pain intensity scores during and after pregnancy, adjusted by determinants in early pregnancy, and presented by groups of estimated absolute oxygen uptake in early pregnancy.

onset of back pain was another limitation. However, in the present study this was to some extent adjusted for by including reported back pain before the present pregnancy in the multivariate analysis.

To the best of our knowledge, no previous study has investigated the influence of oxygen uptake capacity on development of back pain in subsequent pregnancy and postpartum. However, there are studies of non-pregnant populations with back pain that imply an inverse association between aerobic fitness and back pain $[12,17]$ although these findings are disputed by others [18]. In

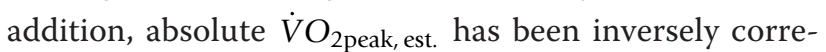
lated with facet degeneration, a significant problem in all chronic low back pain patients although not clearly related to pain [19]. As regards a possible preventive effect of physical activity level on development of pregnancy-related back pain, the results of a retrospective study with its inherent problem regarding recall bias, indicate a decreased frequency of back pain in relation to the amount of regular physical activity before pregnancy [20]. In addition, the cross-sectional methodology used in the above studies made it impossible to evaluate the cause and effect mechanism.

Regular physical exercise reduced pain intensity among pregnant Iranian women but not the frequency of back pain [21]. Lower back pain and neck/shoulder pain has also been found to be inversely associated with regular exercise during pregnancy in a Norwegian study by Owe et al. [22]. This is in accord with the results in the present study where pain intensity was influenced by oxygen uptake and physical activity while the prevalence of back pain was similar to that found in previous studies [2,23-26].

The mechanism underpinning reduced back pain intensity in relation to increased $\dot{V} O_{2 \text { peak, est. and }}$ increased physical activity, respectively, can only be speculated about. Firstly, incipient or present pregnancy-related back pain may have reduced the women's 
ability to perform the ergometer cycle test in early pregnancy. This view is supported by the facts that a higher level of pain before testing is associated with prematurely quitting the bicycle test $[12,27]$ and that maximal exertion in low back pain patients was limited [17]. Secondly, a direct effect of oxygen uptake and fitness on pain perception may be a possibility. Although animal research strongly supports this hypothesis [28] it is disputed in human beings $[29,30]$ and has been shown to only provide temporary relief from pain in healthy individuals [31] and in people with low back pain [32]. Thirdly, there may be co-variation between oxygen uptake and muscular strength, the latter a suggested protective factor for back pain in pregnancy $[33,34]$.

\section{Conclusions}

Oxygen uptake and physical activity in early pregnancy displayed no influence on the onset of subsequent back pain during or after pregnancy, where the time sequence support the hypothesis that poorer physical deconditioning is not a cause but a consequence of the back pain condition. The mechanism for the attenuating effect of increased oxygen uptake on back pain intensity is uncertain.

\section{Acknowledgements}

Kjell Andersson carried out the cycle ergometer tests. The authors thank Professor K. Svärdsudd for invaluable statistical advice.

Funding from the medical faculty, Uppsala University.

\section{Author details}

${ }^{1}$ Department of Public Health and Caring Sciences, Family Medicine and Preventive Medicine unit, Uppsala University, Box 564, SE-751 22 Uppsala, Sweden. ${ }^{2}$ School of Health and Medical Sciences, Örebro University, SE-702 81 Örebro, Sweden.

\section{Authors' contributions}

ET: conceived the study and participated in its design, coordination and acquisition of data, and contributed to analyses and interpretation of data and drafted the manuscript. PK: conceived the study, contributed to analyses and interpretation, and drafted the manuscript. Both authors read and approved the final manuscript.

\section{Competing interests}

The authors declare that they have no competing interests.

Received: 24 November 2011 Accepted: 17 April 2012

Published: 17 April 2012

\section{References}

1. Kristiansson P: Epidemiology of back pain in pregnancy. In Interventional spine an algorithmic approach. Edited by: Slipman CWDR, Simeone FA, Mayer TG. Elsevier: Philadelphia: Saunders; 2008:1307-1310.

2. Kristiansson P, Svardsudd K, von Schoultz B: Back pain during pregnancy: a prospective study. Spine 1996, 21(6):702-709.

3. Olsson C, Nilsson-Wikmar L: Health-related quality of life and physical ability among pregnant women with and without back pain in late pregnancy. Acta Obstet Gynecol Scand 2004, 83(4):351-357.

4. Brynhildsen J, Hansson A, Persson A, Hammar M: Follow-up of patients with low back pain during pregnancy. Obstet Gynecol 1998, 91(2):182-186.
5. Albert $H$, Godskesen M, Westergaard J: Prognosis in four syndromes of pregnancy-related pelvic pain. Acta Obstet Gynecol Scand 2001, 80(6):505-510.

6. Rost CC, Jacqueline J, Kaiser A, Verhagen AP, Koes BW: Prognosis of women with pelvic pain during pregnancy: a long-term follow-up study. Acta Obstet Gynecol Scand 2006, 85(7):771-777.

7. van de Pol G, de Leeuw JR, van Brummen HJ, Bruinse HW, Heintz AP, van der Vaart CH: The Pregnancy Mobility Index: a mobility scale during and after pregnancy. Acta Obstet Gynecol Scand 2006, 85(7):786-791.

8. Kumle M, Weiderpass E, Alsaker E, Lund E: Use of hormonal contraceptives and occurrence of pregnancy-related pelvic pain: a prospective cohort study in Norway. BMC Pregnancy Childbirth 2004, 4(1):11.

9. Kristiansson P, Nilsson-Wikmar L, von Schoultz B, Svardsudd K, Wramsby H: Back pain in in-vitro fertilized and spontaneous pregnancies. Hum Reprod 1998, 13(11):3233-3238.

10. Bjelland E, Eskild E, Johansen R, Eberhard-Gran M: Pelvic girdle pain in pregnancy: the impact of parity Oslo: Norwegian Institute of Public Health; 2010.

11. Verbunt JA, Smeets RJ, Wittink HM: Cause or effect? Deconditioning and chronic low back pain. Pain 2010, 149(3):428-430.

12. Smeets RJ, van Geel KD, Verbunt JA: Is the fear avoidance model associated with the reduced level of aerobic fitness in patients with chronic low back pain? Arch Phys Med Rehabil 2009, 90(1):109-117.

13. Sady SP, Carpenter MW, Sady MA, Haydon B, Hoegsberg B, Cullinane EM, Thompson PD, Coustan DR: Prediction of VO2max during cycle exercise in pregnant women. J Appl Physiol 1988, 65(2):657-661.

14. Lotgering FK, Struijk PC, van Doorn MB, Wallenburg HC: Errors in predicting maximal oxygen consumption in pregnant women. J Appl Physiol 1992, 72(2):562-567.

15. Mottola MF, Davenport MH, Brun CR, Inglis SD, Charlesworth S, Sopper MM: VO2peak prediction and exercise prescription for pregnant women. Med Sci Sports Exerc 2006, 38(8):1389-1395.

16. Astrand $P$, Ryhming I: A nomogram for calculation of aerobic capacity (physical fitness) from pulse rate during sub-maximal work. J Appl Physiol 1954, 7:218-221.

17. Duque IL, Parra JH, Duvallet A: Aerobic fitness and limiting factors of maximal performance in chronic low back pain patients. J Back Musculoskelet Rehabil 2009, 22(2):113-119.

18. Hurri H, Mellin G, Korhonen O, Harjula R, Harkapaa K, Luoma J: Aerobic capacity among chronic low-back-pain patients. Journal of spinal disorders 1991, 4(1):34-38

19. Atalay A, Turhan N, Atalay B: Deconditioning in chronic low back pain: might there be a relationship between fitness and magnetic resonance imaging findings? Rheumatol lnt 2012, 32(1):21-25.

20. Mogren IM: Previous physical activity decreases the risk of low back pain and pelvic pain during pregnancy. Scand J Public Health 2005, 33:300-306.

21. Garshasbi A, Faghinzadeh S: The effect of exercise on the intensity of low back pain in pregnant women. Int J Gynaecol Obstet 2005, 88(3):271-275.

22. Owe KM, Nystad W, Bo K: Correlates of regular exercise during pregnancy: the Norwegian Mother and Child Cohort Study. Scand J Med Sci Sports 2009, 19(5):637-645.

23. Berg G, Hammar M, Moller-Nielsen J, Linden U, Thorblad J: Low back pain during pregnancy. Obstet Gynecol 1988, 71(1):71-75.

24. Ostgaard HC, Andersson GB, Karlsson K: Prevalence of back pain in pregnancy. Spine 1991, 16(5):549-552.

25. Mens JM, Vleeming A, Stoeckart R, Stam HJ, Snijders CJ: Understanding peripartum pelvic pain. Implications of a patient survey. Spine 1996, 21(11):1363-1369, discussion 1369-1370.

26. Bastiaanssen JM, de Bie RA, Bastiaenen $C H$, Essed GG, van den Brandt PA: A historical perspective on pregnancy-related low back and/or pelvic girdle pain. Eur J Obstet Gynecol Reprod Biol 2005, 120(1):3-14.

27. de Gier M, Peters ML, Vlaeyen JW: Fear of pain, physical performance, and attentional processes in patients with fibromyalgia. Pain 2003, 104(12):121-130.

28. Geisser ME, Wang W, Smuck M, Koch LG, Britton SL, Lydic R: Nociception before and after exercise in rats bred for high and low aerobic capacity. Neurosci Lett 2008, 443(1):37-40.

29. Monnier-Benoit P, Groslambert A, Rouillon JD: Effects of steady-state exercise on perceived pain: comparison of sedentary students and cyclists. Percept Mot Ski 2006, 103(3):659-666. 
30. Bruce B, Fries JF, Lubeck DP: Aerobic exercise and its impact on musculoskeletal pain in older adults: a 14 year prospective, longitudinal study. Arthritis research \& therapy 2005, 7(6):R1263-R1270.

31. Kemppainen P, Pertovaara A, Huopaniemi T, Johansson G, Karonen SL: Modification of dental pain and cutaneous thermal sensitivity by physical exercise in man. Brain research 1985, 360(1-2):33-40.

32. Hoffman MD, Shepanski MA, Mackenzie SP, Clifford PS: Experimentally induced pain perception is acutely reduced by aerobic exercise in people with chronic low back pain. J Rehabil Res Dev 2005, 42(2):183-190.

33. Gutke A, Ostgaard HC, Oberg B: Association between muscle function and low back pain in relation to pregnancy. J Rehabil Med 2008, 40(4):304-311.

34. Dumas GA, Leger A, Plamondon A, Charpentier KM, Pinti A, McGrath M: Fatigability of back extensor muscles and low back pain during pregnancy. Clin Biomech (Bristol, Avon) 2010, 25(1):1-5.

\section{Pre-publication history}

The pre-publication history for this paper can be accessed here: http://www.biomedcentral.com/1471-2393/12/30/prepub

doi:10.1186/1471-2393-12-30

Cite this article as: Thorell and Kristiansson: Pregnancy related back pain, is it related to aerobic fitness? A longitudinal cohort study. BMC Pregnancy and Childbirth 2012 12:30.

\section{Submit your next manuscript to BioMed Central} and take full advantage of:

- Convenient online submission

- Thorough peer review

- No space constraints or color figure charges

- Immediate publication on acceptance

- Inclusion in PubMed, CAS, Scopus and Google Scholar

- Research which is freely available for redistribution

Submit your manuscript at www.biomedcentral.com/submit 